\title{
How much of sentence priming is word priming?
}

\author{
RICHARD F. WEST \\ James Madison University, Harrisonburg, Virginia
}

and

KEITH E. STANOVICH

Oakland University, Rochester, Michigan

\begin{abstract}
Sentence primes were compared with two-word primes in three experiments that employed different conditions of context presentation. The two-word primes were created by deleting from the sentence primes function words assumed not to be semantically associated with the target words. Smaller priming effects were found in the two-word condition in all three experiments, and this trend was significant in two of the three experiments. Although a sizable proportion of the sentence priming effect seems to be due to word priming, factors specific to the sentence condition appear to be additional contributors to the effect.
\end{abstract}

In previous research reports (Stanovich, 1986; Stanovich, Nathan, West, \& Vala-Rossi, 1985; Stanovich \& West, 1983), we have argued for a model of lexical access in reading in which word recognition is largely modular. Specifically, in the case of the fluent adult reading nondegraded materials, we have argued that lexical access is not guided by conscious contextual expectancies, but instead that any observed contextual effects are due to spreading activation within the lexicon. Similar models have been supported by several other investigators (de Groot, 1985; Forster, 1979, 1981; Gough, 1983; Henderson, 1982; Seidenberg, 1985a, 1985b; Seidenberg, Tanenhaus, Leiman, \& Bienkowski, 1982).

Our modular model of word recognition, augmented by spreading activation in the lexicon, was derived mainly from experiments on sentence context effects (e.g., Stanovich \& West, 1983; West \& Stanovich, 1982). In this report we examine how much of the priming that is observed in that paradigm can be accounted for by priming from the content words in the sentence. We describe three experiments in which we compared the priming effects produced by sentence contexts (semantic associates and syntactic information intact) with those produced by only the two main content words of the sentence contexts (main semantic associates intact). The three experiments differed primarily in their methods of presenting the stimuli.

\section{EXPERIMENT 1}

\section{Method}

Subjects. The subjects were 80 undergraduate volunteers recruited from an undergraduate psychology subject pool.

This research was supported by National Science Foundation Grant BNS80-20594 to Keith E. Stanovich and by a James Madison University faculty research grant to Richard F. West. Requests for reprints should be sent to Keith E. Stanovich, Department of Psychology, Oakland University, Rochester, MI 48063.
Stimuli and apparatus. The stimuli used in the sentence prime condition were those listed in Appendix A of Stanovich and West (1981). These stimuli were 192 sentences that had been constructed so that their last two words were "the" and a noun that was predictable from the preceding context. The 192 sentences were composed of 96 pairs. The 2 sentences that made up a pair were identical except for their terminal words (e.g., "the skier was buried in the snow" and "the skier was buried in the avalanche"). One of the target words in a pair was a relatively easy word (e.g., "snow"), and the other was a relatively difficult word (e.g., "avalanche"). The mean number of letters in the easy words was $5.0(S D=1.3)$, and the mean number of letters in the difficult words was $7.4(S D=2.1)$. According to Kučera and Francis's (1967) count, the mean frequency of the easy words was 124.3 , and the mean frequency of the difficult words was 7.1. The easy words were more predictable from the contexts (see Stanovich \& West, 1983). The 96 contexts were organized into 48 pairs (e.g., "the skier was buried in the" was paired with "the bodyguard drove the"'). Incongruous sentences were formed by interchanging the target words. The neutral sentence prime was the incomplete sentence "they said it was the."

The stimuli used in the two-word prime condition were identical to those used in the sentence prime condition except that the prime consisted of only the two main content words of the sentence context (e.g., "the skier was buried in the" was reduced to "skier buried"). Most of the words that were deleted from the sentence contexts in forming the two-word primes were function words that expressed primarily grammatical relationships (65\% articles, $18 \%$ prepositions, $8 \%$ copulas, $3 \%$ pronouns, and $6 \%$ other). Thus, in the vast majority of cases, the two words retained were the only content words in the sentence. The neutral two-word prime consisted of the words "they said."

The stimuli were presented on a CRT monitor under the control of an Apple II microcomputer. A Mountain Hardware clock and a voiceactivated relay were interfaced with the computer to enable the collection of the naming times. Target-word onset was controlled by a button that the experimenter pushed immediately after the subject read the prime aloud. This button caused the target to be displayed and simultaneously started the millisecond clock (see Stanovich \& West, 1983, for a detailed discussion of procedural variations in sentence context experiments).

Procedure. The subjects were told to look at the CRT and to read aloud the primes that appeared. In addition, they were instructed to read the target word aloud as rapidly as possible when it appeared. Each subject received a random ordering of 12 practice trials that consisted of 1 trial given under each of the 12 conditions formed by the factorial combination of prime (sentence, two-word), context (congruous, incongruous, neutral), and target difficulty (easy, difficult). Following the practice trials, each subject received a random ordering of 72 experimental trials that consisted of 6 trials under each of the above 12 condi- 
tions. In the experimental trials, each subject saw a subset of 72 of the total population of 192 possible targets. The assignment of targets from the total population was counterbalanced across subjects so that each target was read equally often under each type of prime and context condition. No subject saw the same target or prime more than once in the course of the experiment, and no subject saw more than one member of an easy/difficult word pair or sentence/two-word prime pair. When primes were used in incongruous context trials, the deleted terminal words from the original sentences were never seen by the subject.

\section{Results}

The mean reaction times and the mean percentages of subject errors for all experimental conditions are displayed in Table 1. Also contained in Table 1 are the magnitudes of the overall context effect (the difference between the congruous and incongruous conditions), the facilitation effect (the difference between the congruous and neutral conditions), and the inhibition effect (the difference between the neutral and incongruous conditions). All of the analyses that follow are based on the subject's mean reaction time in each condition.

A $2 \times 2 \times 3$ (prime $\times$ difficulty $\times$ context) analysis of variance conducted on the reaction times indicated that the main effects of difficulty $[F(1,79)=279.6, p<.001]$ and context $[F(2,158)=49.7, p<.001]$ were significant. Reaction times were faster for the easy targets and for the congruous conditions. The main effect of prime was not significant $[F(1,79)<1]$. Both the prime $\times$ context interaction $[F(2,158)=8.2, p<.001]$ and the difficulty $\times$ context interaction $[F(2,158)=9.0, p<.001]$ were significant. Context had a relatively greater influence on naming times for the sentence primes and for the difficult targets. The mean overall context effects for the easy and difficult targets were 33 and $75 \mathrm{msec}$, respectively, in the sentence prime condition, and 15 and $45 \mathrm{msec}$, respectively, in the two-word prime condition. Neither the prime $\times$ difficulty nor the prime $\times$ difficulty $\times$ context interaction was significant $(F \mathrm{~s}<1)$. Planned comparisons indicated that the facilitation effects for both the easy $(41 \mathrm{msec})$ and difficult $(68 \mathrm{msec})$ targets were significant at the .001 level in the sentence prime condition, whereas the facilitation effect was significant only for the difficult targets (26 msec, $p<.001$ ) in the two-word prime condition. The only inhibition effect to reach significance was that for the difficult targets in the two-word prime condition (19 $\mathrm{msec}$, $p<.025)$
The results of an item analysis mirrored those of the subject analysis in all critical aspects. There were significant main effects of difficulty $[F(1,190)=200.9$, $p<.001]$ and context $[F(2,380)=35.5, p<.001]$, but not prime $(F<1)$. Both the prime $\times$ context interaction $[F(2,380)=14.8, p<.001]$ and the difficulty $\times$ context interaction $[F(2,380)=6.2, p<.01]$ were significant. Neither the prime $\times$ difficulty interaction nor the prime $\times$ difficulty $\times$ context interaction was significant $(F \mathrm{~s}<1)$. Both the subject and the item analyses indicated that the difficulty $\times$ context interaction of Experiment 1 replicated that observed in many previous experiments. More importantly, both the subject and item analyses confirmed the key trend in the data of Experiment 1: Sentences produced more priming than did the two-word contexts.

\section{EXPERIMENT 2}

In previous studies of sentence context effects (e.g., Stanovich \& West, 1983), we compared alternative ways of presenting the stimuli. For example, the experimenter initiation procedure employed in Experiment 1 was compared with a fixed interval procedure in which the subject reads the contexts silently (see Fischler \& Bloom, 1979). Experiment 2 was a fixed interval study that is directly comparable with Experiment 1.

\section{Method}

The subjects were 32 undergraduate volunteers recruited through an undergraduate psychology subject pool. The stimuli, apparatus, and procedure were the same as in Experiment 1, except that target-word onset was under the control of the computer rather than the experimenter. The target word appeared 2,400 msec (an estimation of the approximate time needed to read the sentence primes out loud) after the onset of the primes. The subjects were instructed to read the primes silently and then read the target words aloud when they appeared.

\section{Results}

The mean reaction times and the mean percentages of subject errors for all experimental conditions are displayed in Table 2.

A $2 \times 2 \times 3$ (prime $\times$ difficulty $\times$ context) analysis of variance conducted on the reaction times indicated that the main effects of difficulty $[F(1,31)=166.2, p<.001]$ and context $[F(2,62)=11.0, p<.001]$ were significant.

Table 1

Mean Reaction Times (in msec) and Mean Percentages of Errors (\%E) for Experiment 1

\begin{tabular}{|c|c|c|c|c|c|c|c|c|c|}
\hline \multirow[b]{3}{*}{ Word Type } & \multicolumn{9}{|c|}{ Context Condition } \\
\hline & \multicolumn{2}{|c|}{ Congruous } & \multicolumn{2}{|c|}{ Neutral } & \multicolumn{2}{|c|}{ Incongruous } & \multirow[b]{2}{*}{ Facilitation } & \multirow[b]{2}{*}{ Inhibition } & \multirow{2}{*}{$\begin{array}{r}\text { Overal } \\
\text { Contex } \\
\text { Effect }\end{array}$} \\
\hline & Mean & $\% \mathrm{E}$ & Mean & $\overline{\% \mathrm{E}}$ & Mean & $\overline{\% \mathrm{E}}$ & & & \\
\hline \multicolumn{10}{|c|}{ Sentence Condition } \\
\hline Easy & 462 & 0.8 & 503 & 1.3 & 495 & 1.9 & 41 & -8 & 33 \\
\hline Difficult & 581 & 3.1 & 649 & 5.2 & 656 & 2.9 & 68 & 7 & 75 \\
\hline \multicolumn{10}{|c|}{ Two-Word Condition } \\
\hline Easy & 489 & 0.8 & 490 & 0.4 & 504 & 2.1 & 2 & 13 & 15 \\
\hline Difficult & 604 & 3.8 & 630 & 4.2 & 649 & 7.1 & 26 & 19 & 45 \\
\hline
\end{tabular}


Table 2

Mean Reaction Times (in msec) and Mean Percentages of Errors (\%E) for Experiment 2

\begin{tabular}{|c|c|c|c|c|c|c|c|c|c|}
\hline \multirow[b]{3}{*}{ Word Type } & \multicolumn{9}{|c|}{ Context Condition } \\
\hline & \multicolumn{2}{|c|}{ Congruous } & \multicolumn{2}{|c|}{ Neutral } & \multicolumn{2}{|c|}{ Incongruous } & \multirow[b]{2}{*}{ Facilitation } & \multirow[b]{2}{*}{ Inhibition } & \multirow{2}{*}{$\begin{array}{c}\text { Overall } \\
\text { Context } \\
\text { Effect }\end{array}$} \\
\hline & Mean & $\overline{\% \mathrm{E}}$ & Mean & $\overline{\% \mathrm{E}}$ & Mean & $\% \mathrm{E}$ & & & \\
\hline \multicolumn{10}{|c|}{ Sentence Condition } \\
\hline Easy & 523 & 0.5 & 556 & 1.0 & 552 & 0.0 & 33 & -4 & 29 \\
\hline Difficult & 658 & 1.6 & 711 & 3.6 & 713 & 4.2 & 53 & 2 & 55 \\
\hline \multicolumn{10}{|c|}{ Two-Word Condition } \\
\hline Easy & 542 & 0.0 & 554 & 3.1 & 552 & 0.5 & 12 & -2 & 10 \\
\hline Difficult & 674 & 3.1 & 710 & 4.2 & 717 & 4.7 & 36 & 7 & 43 \\
\hline
\end{tabular}

The main effect of prime type was not significant $[F(1,31)$ $=1.3]$. The prime $\times$ context interaction $[F(2,62)=1.1]$, the difficulty $\times$ context interaction $[F(2,62)=1.6]$, the prime $\times$ difficulty interaction $[F(1,31)<1]$, and the prime $\times$ difficulty $\times$ context interaction $[F(2,62)<1]$ all failed to reach significance. Although not significant, the directions of the effects in Experiment 2 were the same as in Experiment 1. The mean overall context effects for the easy and difficult targets in the sentence prime condition ( 29 and $55 \mathrm{msec}$, respectively) tended to be larger than those in the two-word prime condition (10 and $43 \mathrm{msec}$, respectively). Planned comparisons indicated that three of the four facilitation effects were significant but that none of the inhibition effects reached significance.

The results of an item analysis mirrored those of the subject analysis in all critical aspects. There were significant main effects of difficulty $[F(1,190)=128.6$, $p<.001]$ and context $[F(2,380)=13.6, p<.001]$. The results of Experiment 2 were thus equivocal. All of the relevant trends were in the same direction as those in Experiment 1 , but neither the context $\times$ prime nor the context $\times$ difficulty interaction reached significance. Experiment 2 employed a smaller $N$ than that of Experiment 1, and perhaps this reduction in power resulted in a failure to detect effects that were roughly the same size as those in Experiment 1.

\section{EXPERIMENT 3}

In Experiment 3 an attempt was made to replicate the results of Experiment 1 using another stimulus presenta- tion procedure. This was a procedure in which the context words were displayed sequentially to allow more precise control over when each context word was being processed. Such procedures have been used by other investigators (e.g., Forster, 1981; Wright \& Garrett, 1984), and we previously examined a variant of this method (West \& Stanovich, 1986).

\section{Method}

The subjects were 80 undergraduate volunteers recruited through an undergraduate psychology subject pool. The stimuli, apparatus, and procedure were the same as in Experiment 1, except that the primes were presented sequentially from left to right across the CRT. A new prime word appeared every $400 \mathrm{msec}$, and each word stayed on the screen as others were added. A plus sign appeared on the screen before the onset of the first context word. The plus sign indicated the position on the screen where the first letter of the target would appear. When all the words of the context and the target were displayed (target onset was $400 \mathrm{msec}$ after the onset of the last word of the prime), the location that had been occupied by the plus sign was occupied by the first letter of the target. The subjects were instructed to read silently each word of the prime as it appeared and then read the target word aloud when it appeared. In Experiment 3, the subject's reaction time in milliseconds was displayed in the upper left corner of the display after each trial.

\section{Results}

The mean reaction times and the mean percentages of subject errors for all experimental conditions are displayed in Table 3.

A $2 \times 2 \times 3$ (prime $\times$ difficulty $\times$ context) analysis of variance on the reaction times indicated that the main effects of difficulty $[F(1,79)=289.8, p<.001]$, context $[F(2,158)=30.2, p<.001]$, and prime $[F(1,79)=$

Table 3

Mean Reaction Times (in msec) and Mean Percentages of Errors (\%E) for Experiment 3

\begin{tabular}{|c|c|c|c|c|c|c|c|c|c|}
\hline \multirow[b]{3}{*}{ Word Type } & \multicolumn{9}{|c|}{ Context Condition } \\
\hline & \multicolumn{2}{|c|}{ Congruous } & \multicolumn{2}{|c|}{ Neutral } & \multicolumn{2}{|c|}{ Incongruous } & \multirow[b]{2}{*}{ Facilitation } & \multirow[b]{2}{*}{ Inhibition } & \multirow{2}{*}{$\begin{array}{c}\text { Overall } \\
\text { Contex } \\
\text { Effect }\end{array}$} \\
\hline & $\overline{\text { Mean }}$ & $\overline{\% \mathrm{E}}$ & $\overline{\text { Mean }}$ & $\overline{\% \mathrm{E}}$ & $\overline{\text { Mean }}$ & $\overline{\% E}$ & & & \\
\hline \multicolumn{10}{|c|}{ Sentence Condition } \\
\hline Easy & 459 & 0.6 & 468 & 0.4 & 480 & 0.2 & 9 & 12 & 21 \\
\hline Difficult & 541 & 0.8 & 591 & 2.9 & 597 & 1.7 & 50 & 6 & 56 \\
\hline \multicolumn{10}{|c|}{ Two-Word Condition } \\
\hline Easy & 487 & 0.6 & 497 & 0.8 & 491 & 0.2 & 10 & -6 & 4 \\
\hline Difficult & 574 & 2.5 & 585 & 3.1 & 616 & 1.5 & 11 & 31 & 42 \\
\hline
\end{tabular}


$32.2, p<.001]$ were significant. Reaction times were faster for the easy targets, for the congruous conditions, and for the sentence primes. The prime $\times$ context interaction $[F(2,158)=3.1, p<.05]$, the difficulty $\times$ context interaction $[F(2,158)=10.6, p<.001]$, and the prime $\times$ difficulty $\times$ context interaction $[F(2,158)=5.2$, $p<.01]$ were all significant. Only the prime $\times$ difficulty interaction failed to reach significance. Context effects were larger in the sentence condition and for difficult targets. The mean overall context effects for the easy and difficult targets were 21 and $56 \mathrm{msec}$, respectively, in the sentence prime condition, and 4 and $42 \mathrm{msec}$, respectively, in the two-word prime condition. Planned comparisons indicated that only the facilitation effect for the difficult targets $(50 \mathrm{msec})$ was significant in the sentence prime condition $(p<.001)$. Only the inhibition effect for the difficult targets in the two-word prime condition reached significance $(p<.001)$.

The results of an item analysis mirrored those of the subject analysis in all critical aspects. There were significant main effects of difficulty $[F(1,190)=147.6$, $p<.001]$, context $[F(2,380)=27.7, p<.001]$, and prime $[F(1,190)=17.3, p<.001]$. Both the difficulty $\times$ context interaction $[F(2,380)=9.5, p<.001]$ and the prime $\times$ difficulty $\times$ context interaction $[F(2,380)$ $=5.7, p<.01]$ were significant. The prime $\times$ context interaction approached significance $[F(2,380)=2.7$, $p=.07]$, and the prime $\times$ difficulty interaction was not significant.

\section{GENERAL DISCUSSION}

The results of the three experiments indicate that a large proportion of the context effect observed from sentence primes can be attributed to priming arising from the major content words of the sentence Nevertheless, there was a consistent tendency for priming to be larger in the sentence condition than in the two-word condition. The effect is not large, and it was not significant in Experiment 2, but it is probably real. The trend was consistent across three very different methods of stimulus presentation (methods that also consistently confirmed the trend of larger context effects for more difficult target words). Note also that the design of the experiments was biased in the direction of finding equal effects for the two context conditions. This was because the ordering of the words in the two-word condition was maintained from the sentence condition, allowing the possibility that subjects covertly "filled in" the missing function words.

In short, not all of sentence priming seems to be due to word priming. Further investigations need to explore the mechanisms responsible for the differential context effects observed in these experiments. Certainly many such potential mechanisms have been identified in previous studies of configural effects (Auble \& Franks, 1983; Foss \& Harwood, 1975) and postlexical effects in commonly used priming tasks, including naming (Balota \& Chumbley, 1984, 1985; de Groot, 1985; Seidenberg, Waters, Sanders, \& Langer, 1984; West \& Stanovich, 1982).

\section{REFERENCES}

Auble, P., \& Franks, J. J. (1983). Sentence comprehension processes. Journal of Verbal Learning \& Verbal Behavior, 22, 395-405.
Balota, D., \& Chumbley, J. (1984). Are lexical decisions a good measure of lexical access? The role of word frequency in the neglected decision stage. Journal of Experimental Psychology: Human Perception \& Performance, 10, 340-357.

Balota, D. A., \& Chumbley, J. I. (1985). The locus of word-frequency effects in the pronunciation task: Lexical access and/or production? Journal of Memory \& Language, 24, 89-106.

DE GROOT, A. M. B. (1985). Word-context effects in word naming and lexical decision. Quarterly Journal of Experimental Psychology, 37A, 281-297.

FisChLER, I., \& BLOOM, P. (1979). Automatic and attentional processes in the effects of sentence contexts on word recognition. Journal of Verbal Learning \& Verbal Behavior, 18, 1-20.

FORSTER, K. I. (1979). Levels of processing and the structure of the language processor. In W. E. Cooper \& E. Walker (Eds.), Sentence processing: Psycholinguistic studies presented to Merrill Garrett (pp. 27-85). Hillsdale, NJ: Erlbaum.

ForSTER, K. I. (1981). Priming and the effects of sentence and lexical contexts on naming time: Evidence for autonomous lexical processing. Quarterly Journal of Experimental Psychology, 33A, 465-495.

Foss, D. J., \& HARwOod, D. A. (1975). Memory for sentences: Implications for human associative memory. Journal of Verbal Learning \& Verbal Behavior, 14, 1-16.

Gough, P. B. (1983). Context, form, and interaction. In K. Rayner (Ed.), Eye movements in reading (pp. 203-211). New York: Academic Press.

Henderson, L. (1982). Orthography and word recognition in reading. London: Academic Press.

Kučera, H., \& Francis, W. N. (1967). Computational analysis of present-day American English. Providence, RI: Brown University Press.

SEIDENBerg, M. (1985a). Lexicon as module. Behavioral \& Brain Sciences, 8, 31-32.

SEIDENBERG, M. (1985b). The time course of information activation and utilization in visual word recognition. In D. Besner, T. Waller, \& G. MacKinnon (Eds.), Reading research: Advances in theory and practice (Vol. 5, pp. 199-252). New York: Academic Press.

Seidenberg, M., Tanenhaus, M., Leiman, J., \& Bienkowski, M. (1982). Automatic access of the meanings of ambiguous words in context: Some limitations of knowledge-based processing. Cognitive Psychology, 14, 489-537.

Seidenberg, M., Waters, G., Sanders, M., \& Langer, P. (1984). Pre- and post-lexical loci of contextual effects on word recognition. Memory \& Cognition, 12, 315-328.

Stanovich, K. E. (1986). Matthew effects in reading: Some consequences of individual differences in the acquisition of literacy. Reading Research Quarterly, 21, 360-407.

Stanovich, K. E., Nathan, R. G., West, R. F., \& Vala-Rossi, M. (1985). Children's word recognition in context: Spreading activation, expectancy, and modularity. Child Development, 56, 1418-1429.

Stanovich, K. E., \& West, R. F. (1981). The effect of sentence context on ongoing word recognition: Tests of a two-process theory. Journal of Experimental Psychology: Human Perception \& Performance, 7, 658-672.

Stanovich, K. E., \& WeSt, R. F. (1983). On priming by a sentence context. Journal of Experimental Psychology: General, 112, 1-36.

West, R. F., \& Stanovich, K. E. (1982). Source of inhibition in experiments on the effect of sentence context on word recognition. Journal of Experimental Psychology: Learning, Memory, \& Cognition, 8, 385-399.

West, R. F., \& Stanovich, K. E. (1986). Robust effects of syntactic structure on visual word processing. Memory \& Cognition, 14, 104-112.

WrIGHT, B., \& GARRETT, M. (1984). Lexical decision in sentences: Effects of syntactic structure. Memory \& Cognition, 12, 31-45.

(Manuscript received for publication May 16, 1987.) 